\title{
Knowledge Management and Gamification in Pharma: An Approach in Pandemic times to Develop Product Quality Reviews
}

\author{
Ricardo Pateiro Marcão1; Gabriel Pestana ${ }^{2}$ and Maria José Sousa ${ }^{3}$ \\ ${ }^{1}$ Universidade Europeia, Portugal | Altran Portugal, S. A., Portugal \\ ${ }^{2}$ UNIDCOM/ Data Mining Lab, IADE - Faculdade de Design, Tecnologia e Comunicação da \\ Universidade Europeia, Portugal \\ ${ }^{3}$ Instituto Universitário de Lisboa, Business Research Unit, Portugal \\ ricardo.pateiro.marcao@gmail.com \\ gabriel.pestana@universidadeeuropeia.pt \\ maria.jose.sousa@iscte-iul.pt \\ DOI: 10.34190/EJKM.18.03.005
}

\begin{abstract}
The Pharma sector is a much-regulated market, and this means that this industry must test their products to comply with existing standards to assure the required level of quality and safety before being authorized to lunch those products to the market. Supply chains, data integrity, and tightening regulations are just examples of business process issues that affect quality strategies on a day-to-day basis. Besides, regulatory bodies are increasingly focused not only on compliance but also on building a culture of quality management. In this domain, the Quality Management System (QMS) is a well-known system to support processes, procedures, and responsibilities for achieving quality policies and objectives. The QMS also drives consistent metrics, risk calculations, and other trend analysis in developing periodical Product Quality Reviews (PQRs), usually corresponding to one year periods, related to the product and with its active substance. The PQRs development process requires proper management of knowledge so that it can be replicated in different activities. This paper proposes the adoption of Gamification techniques in each phase of PQRs. In pandemic times, it is importante to improve the performance of each activity, gathering the engagement of the employees. Gamification is usually related to employee motivation, which, in turn, is conducive to the achievement of better results in the organization. In this context, it is necessary to understand how the commitment of stakeholders evolves and if the application of Gamification techniques allows enhancing this variable, taking the evolution of the performance as another variable that could be evaluated. This paper focuses on innovation in the area of knowledge management, based on the projection of a Gamified model related to managing activities of a PQR development project at the level of the active substance. The paper presents a case study where the proposed model was applied to analyze the performance achieves in a national pharmaceutical industry in Portugal.
\end{abstract}

Keywords: Gamification, Product Quality Reviews, Public Health, Quality Control, Situational-awareness

\section{Context}

Nowadays, management control systems became strategically useful, responding to the creation of organizational silos. Although this depends on the business model adopted in the context of change management, Chenhall and Euske (2007) and Piras, Giorgini and Mylopoulos (2017) consider these types of systems as an impetus for operational management focused on implementation. Different studies indicate that, as a general rule, incremental innovation mechanisms should be managed differently from radical innovation mechanisms. However, Cardinal (2001) suggests the opposite, focusing on the research and development activities of the pharmaceutical industry. Here, technological innovation has functioned as a driving force for competitive advantage, not only because of globalization, but also because of accelerating product lifecycles, increasing competition, technological fusion, or marketing products across platforms. The cornerstone of competitive advantage in the pharmaceutical industry is the successful innovation, hence the fact that investment in research is far greater than any other industry (e.g., automotive or aeronautical fields). For this reason, organizational control is one of the key points to consider. This can be defined as any process by which managers direct their attention, motivating, and encouraging members of the organization to act the goals of the organization are best achieved. At the same time, structural control, also known as behavioral control, is another pillar to be taken into account as it allows the regulation of activities and behaviors implemented in the form of processes, activities, tasks, and rules. However, in the pharmaceutical sector, formal control mechanisms coexist with strong professional standards, some of which are informal, which also influence values, activities, and outcomes. In the case of the United States of America, the organization that sets these standards is the Food and Drug Administration (FDA), in Europe it is the European Medicines Agency 
(EMA), and in Portugal, specifically, there is the National Medicines Authority (INFARMED), which reports to EMA.

According to World Health Organization (2006), epidemic and disastrous events, like Influenza, Southeast Asian Tsunamis or COVID-19, highlight the urgent need for useful information and knowledge management to coordinate national and international efforts to respond to public health crises. This emphasizes the role of the World Health Organization (WHO) in promoting and assisting member states in the constant and progressive sharing of updated data to improve the quality of information across geopolitical boundaries. Geographic Information Systems (GIS) and other types of information tracking technologies are at the forefront and aim to create information systems and data monitoring related to public health issues. In this context, one of the strategic goals of using a useful knowledge management tool is to leverage international cooperation for proper technical support:

1. Strengthen cooperation with other United Nations organizations, improving data collection, processing and sharing;

2. Promote international and multi-sectoral collaboration, improving compatibility and mapping between different technical solutions under study;

3. Expand the global public health and GIS mapping network.

Different forms of input, behavior, and output control enable scientists to effectively conduct their work and align it with different collaborative and professional goals. Although organizational control influences innovation, it depends on the nature of the product development activity. This paper is composed by the following sections: i) Context, ii) Development of Product Quality Reviews, iii) The Relevance of Knowledge Management, iv) Using the Concept of Gamification, v) Developed Gamification Framework, vi) Methodology and Case Study: Managing Projects in Pharma Industry, vii) Discussion and Conclusions and viii) References.

\section{Development of Product Quality Reviews}

The FDA is responsible for the quality assurance of all pharmaceutical products entering the US market, according to Lawrence and Woodcock (2015). In order to maximize the efficiency and flexibility of manufacturing such products, they should be subject to periodic reviews, called PQRs.

According to Yam et al. (2011) and Hashan et al. (2016), which follows the FDA too, PQRs have annual periodicity when it comes to the active substance. However, when we are talking about products developed in certain manufacturing campaigns, the time interval can be reduced to a smaller number of months.

A PQR report must include the following details:

1. Review of starting materials of used active substance, with particular focus on new sources;

2. Review of critical control processes and final product results;

3. Review of all batches that failed to meet specifications and their investigation;

4. Review of all significant deviations and nonconformities, related investigation and effectiveness of corrective and preventive actions taken;

5. Review of all Changes triggered by analytical processes and methods;

6. Review of variations of marketing authorizations submitted, assigned and refused, including those intended for third countries;

7. Review of the results of the stability and adverse trends monitoring program;

8. Review of the quality of the returned products, complaints and investigation promoted at the moment;

9. Review of Adequacy of other prior product-associated processes or Corrective Action Equipment;

10. Review of post marketing commitments, for new marketing authorizations and variations to marketing authorizations;

11. Qualification status of relevant equipment and utilities;

12. Review of technical agreements.

Since this is a set of activities that can be performed by a team, consider it as a project. In this case, depending on the methodology, we have different guidelines to follow, which infers the process of monitoring the work that was done and the team itself. 
According to Abyad (2012), the project management process involves different areas of knowledge:

1. Integration management;

2. Scope management;

3. Time management;

4. Cost management;

5. Quality management;

6. Human resources management;

7. Communication management;

8. Risk management;

9. Procurement management.

Since the focus is always the same in all areas previously mentioned, Machado, Pinheiro and Tamanini (2015) consider a process defined by five activities to those used in this study:

1. Define and authorize a project in a given area;

2. Define and refine the scope of the project and plan the activity necessary to achieve the desired goal;

3. Train the team, only that the project management plan is followed;

4. Monitor the evolution of the project, allowing corrective actions to take plan;

5. Formalizing the completion of the project through its acceptance by all stakeholders.

\section{The Relevance of Knowledge Management}

According to Keeling (2012), knowledge management is a general term that describes the creation of knowledge repositories and provides better access to it, through communication and collaboration. It is not a single pillar, but an integration between different efforts that contributed to this in a given field of study, be it simple or multiple.

According to the general knowledge model of Ahmady, Nikooravesh and Mehrpour (2016), the reuse of existing concepts should be seen as a mandatory component, and new knowledge is only generated if the concept of ontology in question does not exist. This is characterized by a series of knowledge flows, corresponding to a set of processes, events, and activities, through which data, information, knowledge, and wisdom are transformed into different states. Knowledge creation is the set of activities associated with the entry of new knowledge into the system and includes development, discovery, and capture of knowledge. On the other hand, its retention is the set of activities that preserve it and allow it to remain in the system, so that the viability of knowledge in the system is maintained. This model also includes the transfer and use of knowledge. Knowledge transfer corresponds to the knowledge flow from part to part, including communication, translation, conversion and filtering. The use of knowledge corresponds to the flow of activities and events in which knowledge is applied.

This model organizes and classifies knowledge management methods, methodologies, and technologies, relating them to the different phases within the model and thus creating the so-called good practices. It can be used to examine the flow of knowledge to understand the interactions and dependencies between fragments of information and their issuers or receivers.

Knowledge management is a range of techniques and processes that aim to create, represent and distribute knowledge, with the aim of improving organizational performance, stimulating innovation and sharing lessons learned. The intervention of human and technical or computational components is usual. The latter allow for the integration of information from various sources to support the modus operandi, decision making and the way the processes are carried out.

In the scientific field, knowledge management is rooted in different disciplines, including business and management, economics, education, information management, psychology and sociology. These areas have developed perspectives on the functioning of individual and systematic knowledge. Knowledge management embraces these perspectives, but considers that people acquire knowledge through the execution of established organizational processes and routines, the totality of which is humanly impossible to acquire. However, the routines associated with each one evolve according to their adaptation, in response to external stimuli, which makes knowledge management adapt to each situation. In this context, this allows to improve 
the creation, acquisition, structuring, formalization, recovery, maintenance and application of an organization's knowledge, also known as the knowledge life cycle.

According to World Health Organization (2006), nowadays due to technological advances, investment in training and the establishment of procedures and processes, globally speaking, GIS are used in order to map the global distribution of infectious diseases and related risk factors. These systems have also facilitated surveillance for the purposes of early warming and the planning and implementation of disease prevention and control measures.

In this sense, WHO has developed a work program that focuses on four strategic directions:

1. Mapping basic public health resources and risks at the local level, provided by the efforts of world leaders;

2. Promotion, improvement and evaluation of GIS tools for disease surveillance and strengthening of health systems;

3. Strengthening national decision making through the use of mapping between public health issues and GIS;

4. Leveraging international cooperation for the project to implement GIS standards, methodologies, tools, data and technical support.

One of the strengths of GIS and public health mapping is the standardization of data from the local level to the global level, as well as through diseases. Here we speak specifically about the global surveillance of these and the links between different sectors, health interventions and programs, as is the case of the pandemic situation in which we live today, due to COVID-19. To complete the image mapping tools, GIS and public health, an analysis of relational health data is made from a wide variety of sources, constituting a properly structured base. Here, knowledge management is used to ensure good decision making.

Taking another example, when a school map at district level is superimposed on a water distribution map, WHO programs can quickly identify schools with children and adolescents at higher risk for infection with a given infectious disease, dramatically reducing the number of children that need to be identified and tested.

The public health and GIS mapping tools, methodologies and technical support are integrated in different researches at the level of Service Availability Monitoring (SAM), with the due collaboration of the local health delegations. The purpose of this service is to quickly assess the capacity of the health units and respective services in the districts and regions, in order to identify where there is a greater shortage of resources.

As a contribution to knowledge, improving evidence for decision making, WHO developed the Global Health Atlas (GHA). This can be accessed through the internet, contemplating the possibility of consultation, mapping, reporting and interactive analysis of public health data, from diseases to treatment, also monitoring rates of treatment success and mortality by country and region.

According to Yam et al. (2011) and Hashan et al. (2016), the use of this platform is extremely important for pharmaceutical companies. Every time that they need to develop a PQR report about some active substance or another type of chemical product, which is or would be a final product, it is useful to make proper knowledge management and to consult it in order to analyze pieces of information about the disease to be treated with this product.

\section{Using the Concept of Gamification}

Although the studies surrounding performance management involve the public health and professional services' sectors, Bradley et al. (2012) consider it as a topic that quickly covers the other sectors. In order to design, implement and manage new health information systems, through the development of an enterprise architecture capable of capturing the effectiveness of IT and business resources, Bradley et al. (2012) define two types of input: i) financial motivations and various types of inter-organizational relationships, and (ii) pressure from patients who want health professionals to meet patients' needs, which supports technology in the perspective of providing a greater amount of resources electronically. Based on these inputs, it concludes that the relationship between the maturity stage of the business architecture and the organizational impact of 
the use of IT is directly proportional, in a positive perspective, since its implementation allows organizations to obtain a greater competitive advantage.

In this sense, as we evolve in the maturity stage of the enterprise architecture, we are able to address the different types of motivation defined previously. According to Ryan and Deci (2000), despite the observable evidence that humans are endowed with intrinsic motivational tendencies, this propensity is expressed only under specifiable conditions, which contrasts with extrinsic motivation.

In the perspective of studying the evolution of performance management, Harrison and Qin (2009) develop a method to discriminate failures, through a predictive control model. This method monitors the sequence of innovations of the Kalman filter, which can be obtained in closed industrial circuit, from where we can make an analogy to the use of the concept of Gamification. According to the benchmarking study carried out by the author, the final result of the application of the method is an indication of the estimation of the sub-optimal state, which revealed the method contributes to the capture of the high yield.

With the objective of producing a process of continuous improvement of a given economic activity, Kang and Han (2008) analyze the performance of its management activities and states that the use of a Business Activity Monitoring (BAM) system can be used to monitor performance management in real-time. Since a system of this kind monitors several enterprise systems simultaneously and shows exceptional situations in a dashboard, in case the symptoms of the problem are identified by predefined rules, Kang and Han (2008) consider it as a solution that feeds the globalization of the economic activity of the organization. However, since the good financial performance of an organization should follow the motivation of its employees, according to Besley and Robinson (2010), the enterprise architecture must contain a management control system capable of dealing with change, not only at the macroeconomic level, but including human resources and strategic and organizational planning, according to Chenhall and Euske (2007). The study conducted by Cardinal (2001), indicates that control at the level of a business process can be defined as any process by which managers direct attention, motivate, and encourage the members of the organization to act in the desired way to achieve the company's goal.

Business effectiveness is one of the essential activities in organizations focused on service delivery, being present in the tertiary economic sector. According to Osipov et al. (2015), to use motivation as a contribution of gamification models, it is necessary to understand how we can monitor employees' performance, with which it agrees Kang and Han (2008), also indicating that incentives and rewards, whether intrinsic or extrinsic, are critical elements for gamers in any context.

An application's example of this models' type to commercial efficacy is the analysis collected by Marcão, Pestana and Sousa (2017), which made an on-site observation through the analysis of data made available by a Business Activity Monitoring (BAM) system, with the objective of the monitoring of the performance of the automotive industry in real time. Since the company is dispersed geographically, real-time monitoring is more than essential for continuous improvement of its processes. Being difficult to monitor and analyze business events, in an integrated and comprehensive way, due to the location and source of the information systems for performance measures, the BAM system was proposed with the most promising solution to complete all the needs.

According to Marcão, Pestana and Sousa (2016), business performance management allows organizations to monitor and respond to changes in the business environment, in order to optimize their performance, relating it to the employee's goals. Business performance is measured through indicators to reflect the return of activities under the technology layer.

For the best performance in the business, the essential is the set of effective measurement and performance analysis of the management activities of the business, which is only possible through the definition of indicators, metrics used to plan, execute and monitor business. Among these, performance indicators are highlighted, which determine the monitoring of the objectives to be fulfilled and allow the monitoring of the relative levels of control with a certain tolerance, used in the organizational context.

In the health sector, commercial efficiency is not measured by sales performance but rather by the quality of health care. In order to perform such management, Singh (2012) reviewed the methods most commonly used 
in this type of control, especially in cardiac surgeries. Although its area is cardiology and not management or computer science, the researcher wanted to study the usefulness of certain types of graphics used in dashboards to monitor health care performance, such as control charts, Cumulative Sum Charts (CUSUM) and funnel plots. As a conclusion to the study and application of the developed dashboard, the CUSUMs analysis was clearly the most acceptable for the evaluation and monitoring of the medical processes in question. It should be noted that further work on this point does not compare with a study on the effectiveness and/ or efficiency of a conventional dashboard and should not therefore be assessed in the same way.

In the pharmaceutical sector, commercial efficiency follows the organizational model of professional services, related to the so-called sales energy. According to Cardinal (2001), after a study of 57 disparate pharmacists, formal control mechanisms coexist with strong informal professional standards that also influence values, activities, and outcomes. In this configuration, input, behavior, and output control, in the context of product development, can enable scientists to effectively conduct their work and align it with professional norms and goals. The basis of competitive advantage in the pharmaceutical industry lies in successful innovation. For this reason, the pharmaceutical industry spends a large percentage of the value of its sales in research and development, unlike other industries, such as those related to the aerospace industry or the development of advanced technology. In this context, the author reinforces that control can be defined as any process whereby top management focuses attention, motivates, and encourages employees to act in a planned way to achieve the company's annual fiscal goals. Associated with this, there is another type of control, structural control, also known as bureaucratic or behavioral control, since it allows regulating the organization's business activities and is often implemented in the form of rules and procedures.

Despite the potential benefits of implementing information systems and technologies in the health sector, their effectiveness and success are limited by cultural and regulatory concerns. According to Bradley et al. (2012), these obstacles can interfere in the alignment between IT and the organization's business, which has an impact on the evaluation of its commercial effectiveness. Although the correct leverage of IT can provide strategic skills to health professionals with commercial responsibilities, regulatory agencies and competition in the sector may be an obstacle, as it requires organizations to adapt to their characteristics and, sometimes, their own economic activity.

In the context of performance management of a collaborator, its performance always appears as a variable dependent on motivation, where we can study the benefits of using the concept of Gamification. According to Marcão, Pestana and Sousa (2017), the main objective of this concept is to improve the motivation of the human being and his performance in a given activity, and the motivation can be leveraged by the systematic addition of benefits. Depending on the results obtained in the projection and development of products or services, it is possible to transform the professional activity of a collaborator in a game, which is possible through the definition of indicators. According to Herzig, Ameling and Schill (2012), indicators are metrics used to plan, execute and monitor business strategies, to highlight key performance indicators (KPIs), key control indicators $(\mathrm{KCl})$ and key risk indicators (KRI). These determine the monitoring of the objectives to be fulfilled and allow the monitoring of the relative levels of control with certain tolerance, used in the organizations. Since the concept of Gamification refers to a process that allows the improvement of a service, according to the research project conducted by Marcão, Pestana and Sousa (2017), through the creation of value triggered by the collaborator himself, his potential is based on motivational support. This is distinguished into two types: i) intrinsic and ii) extrinsic. In case i), the motivation is rooted directly in a given task, while in case ii) the motivation is related to an economic compensation.

In the perspective of Herzig, Ameling and Schill (2012), Gamification is considered as the new trend of capturing high performance in organizations, being a concept also used to improve employee engagement. This approach is especially promising in the business domain as business information systems focus on efficiency issues, rather than focusing on points such as motivation and satisfaction. In order to use this concept in the organizational context, business information systems responsible for business management and business effectiveness can act as mediators for introducing gaming techniques such as scorecards or rapid feedback on real business processes. From a psychological perspective, Marcão, Pestana and Sousa (2016) concludes that it produces significant improvements in employees.

According to the guidelines defined by Deterding et al. (2011), to acquire added value through the use of business architectures: i) avoiding the traditional approach in strategic planning, ii) outlining a future strategy 
that maximizes the current performance, and iii) evaluating the intermediate effects of the use of IT to generate added value; an enterprise architecture must be designed to capture maximum flexibility and agility. Kang and Han (2008) further emphasize that this point should be valued in order to improve the alignment between business and IT, from where IT projects has an architecture based on a gamification model, using different events. In the architecture presented, game rules are created and managed through a Business Rule Management System (BRMS) and the engine evaluates each event according to its predefined game rules. This offset event is, in turn, processed by the game repository and stored in its database. Finally, an analytical component is used to analyze player behavior in order to improve the rules of the game and optimize longterm employee engagement.

\section{Developed Gamification Framework}

Gamification in a standard context can be translated as a competition that is created where a number of people perform activities to score points and to win their league, in the case that has different profiles playing in more than one league, with which agree Landers et al. (2018). The activities are related to their normal activities with some stretch targets to enhance performance and to distinguish between players. Figure 1 shows a diagram that elucidates the background where gamification, as a way to enhance people performance and solve the lack of their adherence, may work.

It is a framework that provides a continuous improvement cycle of $20 \%$ overall for each iteration, as we can see in figure 2. This framework is based on four stages, numbered from 0 to 3, which are described in table 1.

Starting with Stage 0 (Assess), interviews should be conducted with the various interlocutors of the management of the company concerned, to understand which areas most need intervention. In addition to the results, it is also necessary to measure the behavioral component so that the indicators are aliogned with the different profiles.

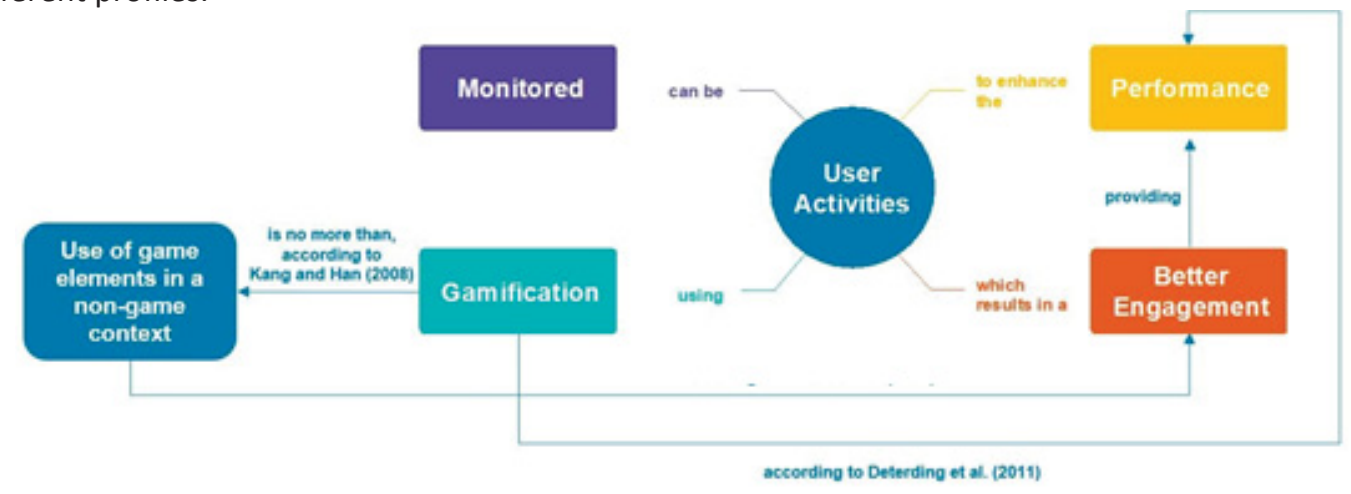

Figure 1: Gamification background

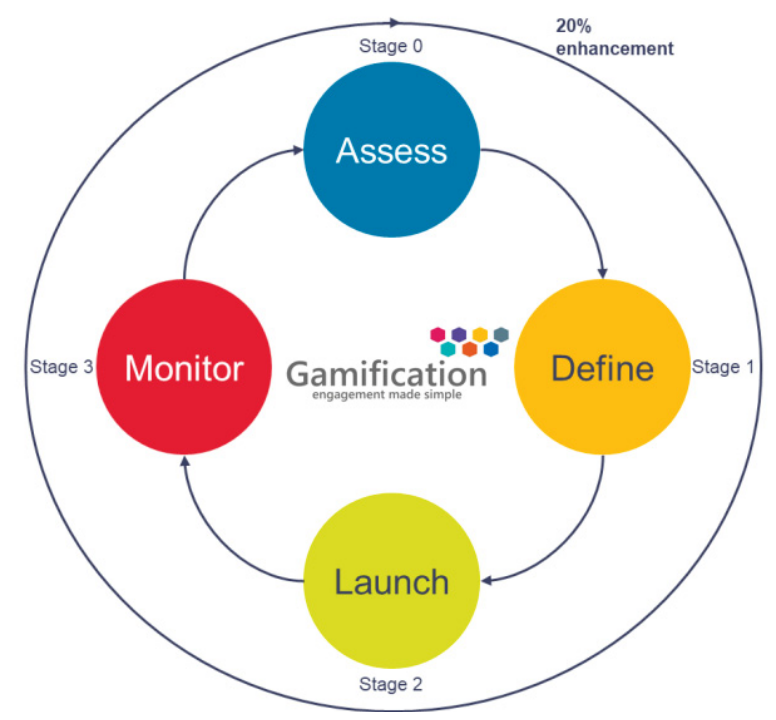

Figure 2: Gamification framework 
In Stage 1 (Define), the communication groups, called leagues, when applicable, are defined according to the alignment between the professional and behavioral profile of each employee; as well the size of the teams that will be part of each league and the number of teams that should be playing. In addition, they are defined different analysis indicators of three typologies: KPIs, KRIs and $\mathrm{KCls}$; and they should have a weight of $50 \%$, $30 \%$ and $20 \%$, respectively. Using biomimicry, calculation rules should be defined to allow them to be measured using the first ten levels of the Fibonacci sequence as a standard. At this stage, it is still necessary to define the timeline in which the program will run, control model and used technology for data collection and result sharing.

Table 1: Stages of the gamification framework

\begin{tabular}{l|l}
\hline \multicolumn{1}{c|}{ Stages } & \\
\hline 0: Assess & Areas/ topics to be improved \\
\hline 1: Define & Indicators that should be measured \\
\cline { 2 - 2 } & Leagues according to the profiles in each area to be improved \\
\cline { 2 - 2 } & Dimension of the teams \\
\cline { 2 - 2 } & Number of leagues \\
\cline { 2 - 2 } & Used technology \\
\cline { 2 - 2 } & Timeline of the program \\
\cline { 2 - 2 } & Number of teams \\
\hline \multirow{3}{*}{ 2: Launch } & Gamification program \\
\hline & Teams \\
\cline { 2 - 2 } & Indicators \\
\cline { 2 - 2 } & Engagement of the people \\
\cline { 2 - 2 } & Results \\
\cline { 2 - 2 } & Score evolution \\
\hline
\end{tabular}

In Stage 2 (Launch), the gamification program is presented, with all leagues, their teams and indicators, expected timeline and the prize (or prize typology) that the winning people will award. As we can see in the conceptual map of figure 3 , this type of program allows to improve performance by measuring indicators, addressing both intrinsic and extrinsic motivation.

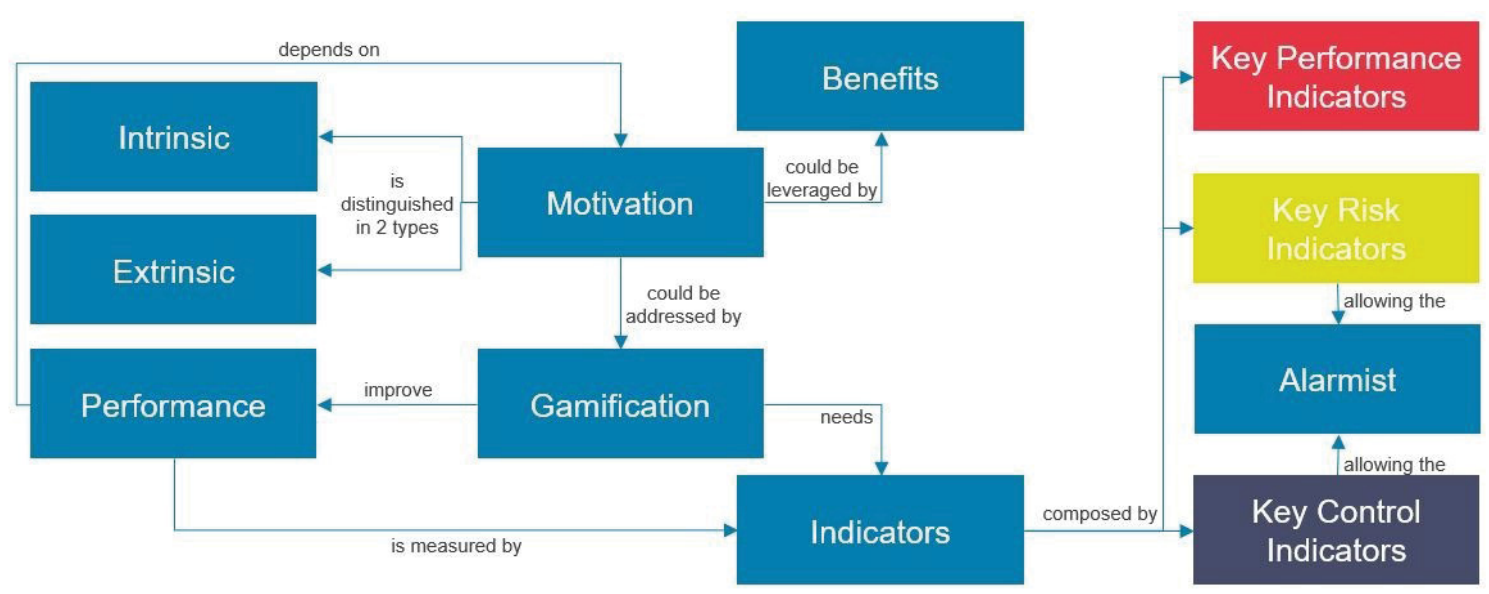

Figure 3: Conceptual map correlating motivation and indicators

In Stage 3 (Monitor), the entire control model is applied. The results achieved by each indicator are present, against the predefined goal (20\% of enhancement), evolution of the score of the teams and level of engagement. When we have more than one league, whenever the overall engagement level (arithmetic mean between leagues) decreases, a boost should be applied to boost the players participation.

The application of this framework is foreseen in two approaches: i) top management and ii) project management. In this paper, it will be discussed only the approach to project management, where there is the 
particularity that only two types of indicators are considered: KPIs and $\mathrm{KCls}$, with a weighting of $50 \%$ each, since risk management is one of the pillars of project management practice, according to Abyad (2012). As it can be seen in figure 4, a project management approach considers that KPI measure the performance agains key business objetives and $\mathrm{KCl}$ measure the monitorization relative to desired tolerances.

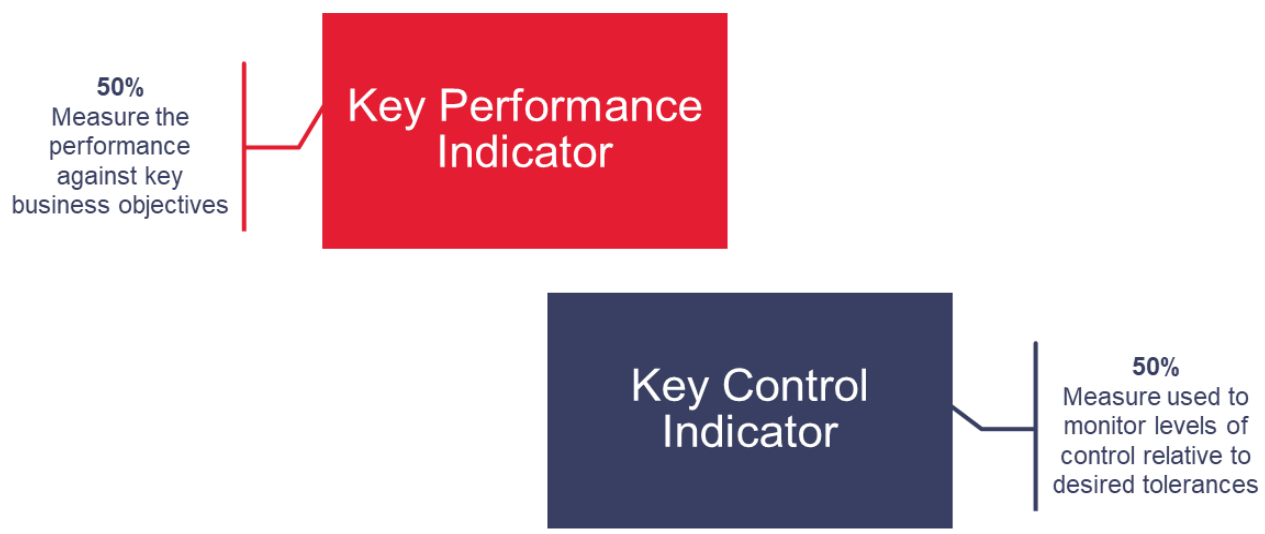

Figure 4: Project management approach

\section{Methodology and Case Study: Managing Projects in Pharma Industry}

Based on an identified lack in management process, already reffered in previous sections, there were defined the following research questions, which derive from the literature and the empirical work that was been performed:

1. What procedures may allow the monitoring of business activities efficiently?

2. What are the motivational factors that may contribute to increase the professionals' performance of a consulting company?

3. How to define a scale to quantify the recognition of those professionals, based on their performance?

4. What is the relationship between a reward system and the effectiveness of those professionals, in particular as regards the goals to be met?

To answer those questions, it is important to know what kind of services may have a consulting company. According to Turner (1982), consulting is not just give an advice, but also add the proper value to enhance something related to their expertise, which fits in the following scope: i) Business, ii) Engineering, iii) Technology or iv) Life Sciences. In order to clarify, Business is related to management services, Engineering is related to technical advisory services; and Life Sciences is related to pharma and health services. Even working under scopes totally different, all of these services have projects with the same macro-phases: i) Assessment, ii) Development of the artifacts, and iii) Deli er the arterfacts.

Specifically, in the case of Technology, the Development is composed by three sub-phases: i) functional analysis, ii) technical analysis, and iii) applicational development; and the Delivery is composed by other two sub-phases: i) tests and ii) final delivery. According to the chosen methodology, these phases can be sequential or iterative. Taking an example, in the functional analysis phase, it is common to have a product identification as well as requirements gathering with business experts to create the product "to be", a process that consumes time and requires some training in the area, so that it could be understood business process mapping. The applicational development phase corresponds to the technological implementation period of a tool in study, and it is not always possible to efficiently monitor the tasks of the team. For this reason, this gamification framework was projected to be based on ISO 42010 standard, bringing together the good practices of practices of project management methodologies, so that team monitoring moments are defined. During these moments, the evolution of the work performed is validated and the people's ambitions and motivations are identified, assessing their project evolution perspective, following a path for the success, as suggested by Asraf and Aftab (2017). If the consulting kind were other, these examples of application should fit in the Assessment and Development phases, respectively as well. 
Since the motivation of the consultants can have different natures, it is necessary to define a system that allows the quantification of this concept. One possible solution is the creation of a system based on the concept of gamification, where it is necessary to define a sufficiently fair scale that allows different consultants to compare with each other, regardless of their nature (technical, or functional).

To address initial needs, it was considered a conceptual model (see figure 5), where different propositions were identified that are intended to be validated:

Q1: the different project management methodologies and processes allow us to address the motivation of contributors;

- Q1.1: The motivation identified has a nature intrinsic;

- Q1.2: The motivation identified has a nature extrinsic;

Q2: Motivation directly influences employee's performance;

- Q2.1: The evolution of employee's performance evolves positively;

- Q2.2: Evolution of employee's performance evolves negatively.

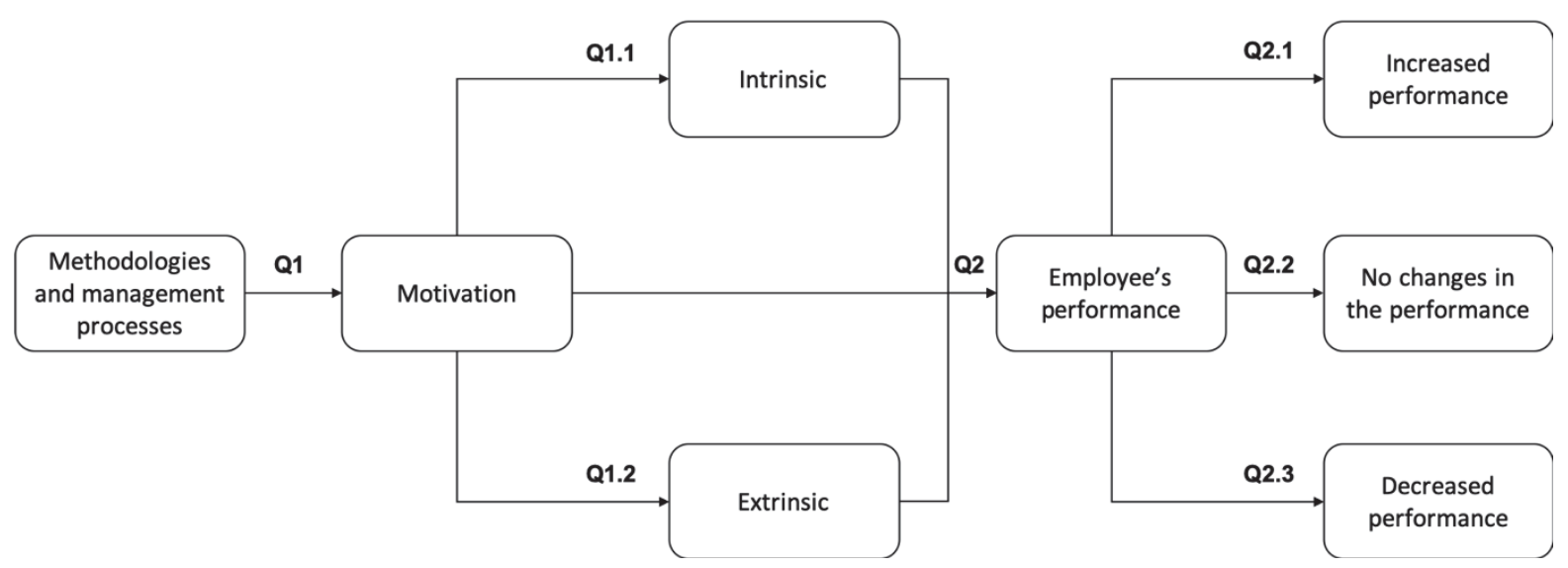

Figure 5: Conceptualization of the propositions previously identified

To fulfill the proposed objetives of the research work, it was decided to use qualitative methods. To that population involved in the case study, interviews were conducted with the objective of analyzing their performance; and surveys were conducted to analyze their commitment. To support such moments, the data on the performance, control and risk indicators of each individual (when applicable) were analyzed in advance.

Altran Portugal, S. A. has a proprietary methodology for managing the entire project lifecycle, called the Altran Delivery Management System (ADMS). This concept is related to a project where it can has different natures, which may be related to time and materials (through awarding competencies or work hours), closed project or service (with or without Service Level Agreements (SLAs)). ADMS is a Capability Maturity Model Integration (CMMI) Level III based methodology that is dynamic enough to adapt to methodologies such as Waterfall and Agile typologies, although it defines standard rules that we must follow, such as the minimum number of interactions with the client and Altran project team.

Since the concept of Gamification is applicable to any activity, it was decided to apply a gamification model to the management of one of Altran's pharmaceutical projects related to the production of PQRs through a Focus Group. Such a model merely focuses on the monitoring of two indicators, with the aim of control a project implementation: $\mathrm{KPI}$ and $\mathrm{KCl}$. The project team was composed by six people: i) four technical consultants (two juniors and two seniors, with the additional objective of reviewing the work of the junior consultants), ii) a project manager and iii) a sponsor. The gamification model was only applied to technical consultants.

Over three months, all predefined tasks in project implementation were measured according to two basic metrics for the calculation of $\mathrm{KPI}$ and $\mathrm{KCl}$, respectively: i) complexity and ii) time. Twice a week (every Tuesday and Thursday), the technical advisors were monitored according to the complexity of each task assigned and the effort required to perform each task, with a weighting of $50 \%$ each. Using the first ten positions of the 
Fibonacci sequence, each completed task offered a score between 1 and 55 points for each consultant, whose evolution we can analyze in figure 6.

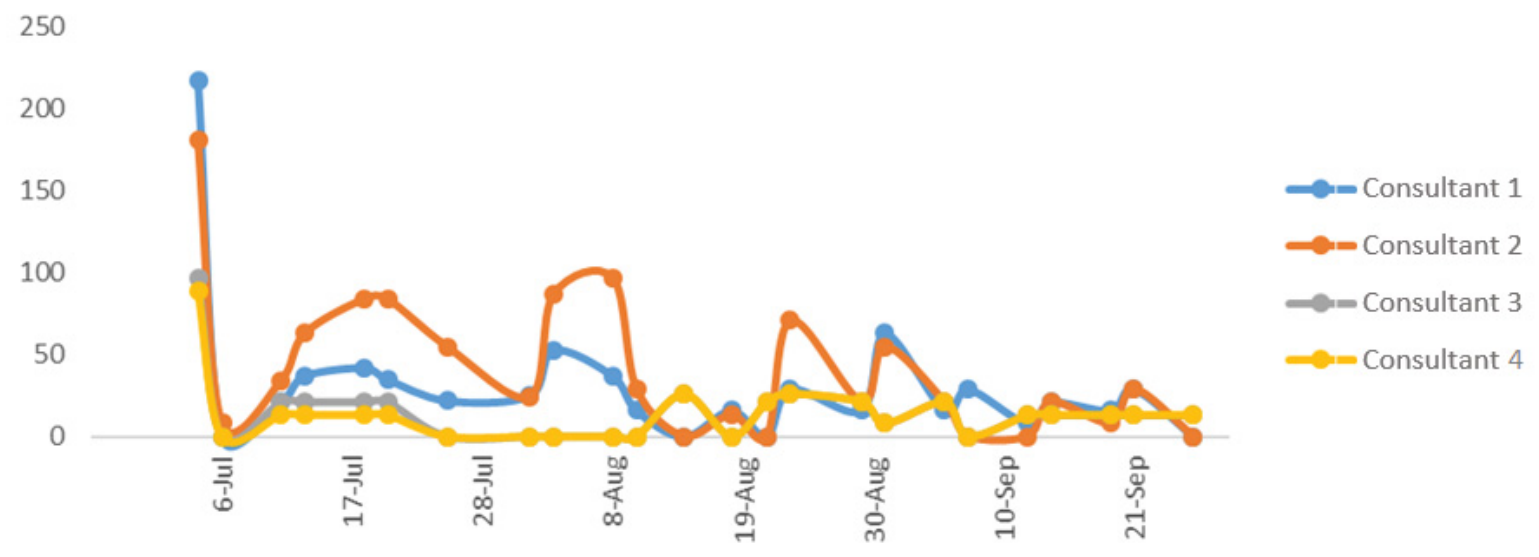

Figure 6: Score evolution of the consultants

Looking at the previous chart with some particularity, we can easily identify two weak consultants (3 and 4) and two strong consultants (1 and 2), whose cumulative performance we can analyze in figure 7.

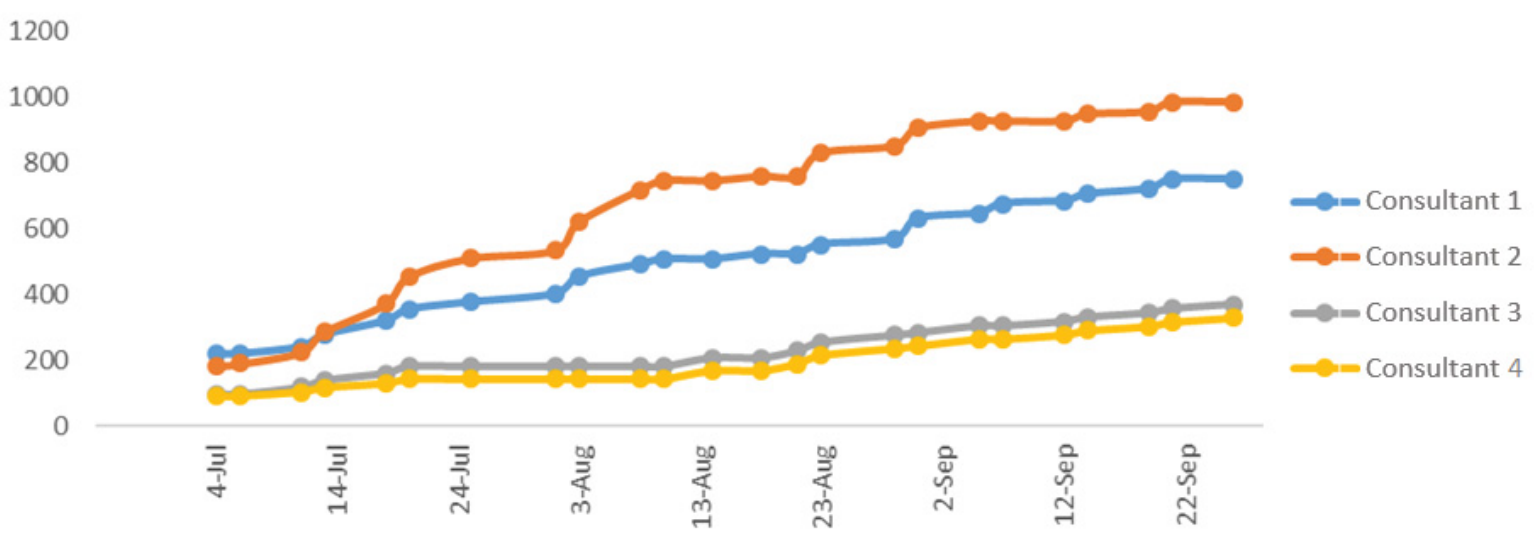

Figure 7: Cumulative score evolution of the consultants

Although consultant 1 started the project with better performance than consultant 2, consultant 2 is able to improve it with gradual growth from the fourth monitoring moment.

After conducting individual and group interviews, it can be seen that the fact that there is $100 \%$ transparency in the collection of the results, being the individual score shared at all times with the whole team, acts as an innate impulse to obtain the best rating. This is justified by Sailer et al. (2017) as an impulse that generates player satisfaction by being aware of the actions of other players and the overall performance of the group.

Applying this methodology helped us finish the project sooner than expected, with an approximate $20 \%$ reduction in effort and the top two were awarded a monetary productivity premium. As a result of the financial instrument applied to this project, there was a full release of the project's risk pool, as well as $25 \%$ of the projected costs.

\section{Discussion and Conclusions}

Throughout the previous sections, the topic of performance management was addressed in different perspectives, focusing on the importance of defining and using different business overviews and mechanisms to capture the high performance of organizations, which is only possible through maximizing motivation of its employees. 
Keeling (2012) considers that the knowledge creation represents a pack of activities related to the new knowledge as an input for a system and includes development, discovery and knowledge capture. The knowledge is the key for the activity in every scope, including the protection of public health. It allows us to enhance the development, discovery, communication, translation, conversion, maintenance and application of this knowledge.

Despite the observable evidence that humans are liberally endowed with intrinsic motivational tendencies, according to Deterding et al. (2011), this propensity is something expressed only under specific conditions.

According to Ryan and Deci (2000), feedback is one of the most important tools of organizations, as it allows employees to evaluate their performance, contrasting their results in a temporal perspective.

According to Chenhall and Euske (2007), the role of Management Control Systems (MCS) has become an important concern for professionals and researchers in the fields of economics and management, regarding different organizational changes. With the use of the area under focus in this document, it is possible to carry out a statistical analysis with different parameters, defined by presented indicators in used gamification model, which it agrees Bradley et al. (2011). According to Marcão, Pestana and Sousa (2019), based on this type of models, it is possible to monetize the invested capital, which, in turn, shows the benefit of the teams in play.

Using the same specification for $n$ conceptual models, changing only the indicators and the emphasis of the identified use cases, it becomes easier to create value through the perception of the business. Thus, according to Ayachitula et al. (2007), the alignment between existing and required processes is achieved faster and therefore with a higher success rate, while still guaranteeing one of the high-performance principles of IT, with which agrees Dvorak et al. (1997). However, despite the clear and necessary use of technology to the detriment of human morality and citizens' rights in many cases studied, monitoring is a seemingly essential term for organizations. If it is evaluated the simplest case of third-party monitoring not explicitly authorized by the employees concerned - monitoring the e-mail box - it can be shawn a gap created between top managers and low-grade employees who feel some invasion of privacy. Top managers point out that it is extremely important that this should remain in place, unlike low-level collaborators, for using e-mail as a communication tool among co-workers and not only for themes stemming from the work they do, states Robinson (2001). According to the guidelines presented by Marcão, Pestana and Sousa (2019), to acquire added value through the implementation of business architectures with gamification models: i) avoid the traditional approach in strategic planning, ii) outline a future strategy that maximizes the current performance, and iii) evaluate the intermediate effects of IT use for the generation of added value; an enterprise architecture must be designed to capture maximum flexibility and agility so that drivers of effective motivation can be used, such as the concept of Gamification under study.

Remembering all research questions that were approached in the previous section, it can be synthetized their answers. About the first question - What procedures may allow the monitoring of business activities efficiently? - this gamification framework preview four stages of a life cycle: i) Assess, ii) Define, iii) Launch and iv) Monitor. According to the assessment that results from the first stage, we define the pack of indicators applicable for each profile. After the launch of gamification program, we can monitor regularly all indicators, being KPIs, KCls and KRIs. If we are talking about the project management approach, these indicators should be measured twice a week. If we are talking about the top management approach, these indicators should be measured monthly.

About the second question - What are the motivational factors that may contribute to increase the professionals' performance of a consulting company? - to validate this gamification framework, it was used also the Allen and Meyer's scale to measure the commitment of the employees. It was applied before and after each competition and the results have been showed that different profiles have different changes on their commitment sense. However, all profiles reached out a better performance when they were applied boosts into the game, which allows to conclude that no one, independent on the profile, like to be on the bottom, when the competition is public to all company.

About the third question - How to define a scale to quantify the recognition of those professionals, based on their performance? - this gamification framework uses Fibonacci sequence to measure all indicators and to set 
the results of all teams. This scale is very good with questions like this because above the level 5 ( 5 points), the results are insignificant, but after the level 5, the results are increasing the score in a quick way to reach the top (level $10=55$ points). At the stage 1 (Define), theay are not just define the pack of indicators for each profile, but also the way to measure each one. When in the presence of a KPI (measured with $50 \%$ ), the rules need to be stronger than the $\mathrm{KCls}$ or KRIs.

About the fourth question - What is the relationship between a reward system and the effectiveness of those professionals, in particular as regards the goals to be met? - according to the analysis of the interviers, with a reward system measured regularly (twice a week or monthly, depending on the chosen approach), it is easier to achieve the goals. These two situations are directly dependent from each other. After all, at the stage 0 (Assess), it is necessary to understand what is/ are the desire(s) for each profile, so the employees can be satisfied with the achieved results of the competition.

As a future work for the continuity of this research, it is proposed another Focus Group to test this gamification framework, but using the approach for top management. It may gives us a different point for the research.

\section{References}

Abyad, A., 2012. Project management: the challenge the dilemma. Middle East Journal of Business, 55(3219), pp.1-5. Ahmady, G.A., Nikooravesh, A. and Mehrpour, M., 2016. Effect of organizational culture on knowledge management based on Denison model. Procedia-Social and Behavioral Sciences, 230, pp.387-395.

Ashraf, S. and Aftab, S., 2017. Latest transformations in scrum: a state of the art review. International Journal of Modern Education and Computer Science, 9(7), p.12.

Ayachitula, N., Buco, M., Diao, Y., Maheswaran, S., Pavuluri, R., Shwartz, L. and Ward, C., 2007, July. IT service management automation-A hybrid methodology to integrate and orchestrate collaborative human centric and automation centric workflows. In IEEE International Conference on Services Computing (SCC 2007) (pp. 574-581), Salt Lake City (Utah, USA), July 2007. IEEE.

Besley, T. and Robinson, J.A., 2010. Quis custodiet ipsos custodes? Civilian control over the military. Journal of the European Economic Association, 8(2-3), pp.655-663.

Bradley, R.V., Pratt, R.M., Byrd, T.A., Outlay, C.N. and Wynn, Jr, D.E., 2012. Enterprise architecture, IT effectiveness and the mediating role of IT alignment in US hospitals. Information Systems Journal, 22(2), pp.97-127.

Cardinal, L.B., 2001. Technological innovation in the pharmaceutical industry: the use of organizational control in managing research and development. Organization Science, 12(1), pp.19-36.

Chenhall, R.H. and Euske, K.J., 2007. The role of management control systems in planned organizational change: An analysis of two organizations. Accounting, Organizations and Society, 32(7-8), pp.601-637.

Deterding, S., Dixon, D., Khaled, R. and Nacke, L., 2011, September. From game design elements to gamefulness: defining" gamification". In Proceedings of the 15th international academic MindTrek conference: Envisioning future media environments (pp. 9-15), Tampere (Finland), September 2011.

Dvorak, R.E., Holen, E., Mark, D. and Meehan, W.F., 1997. Six principles of high-performance IT. McKinsey Quarterly, pp.164-179.

Harrison, C.A. and Qin, S.J., 2009. Discriminating between disturbance and process model mismatch in model predictive control. Journal of Process Control, 19(10), pp.1610-1616.

Hashan, H., Aljuffali, I., Patel, P. and Walker, S., 2016. The Saudi Arabia Food and Drug Authority: an evaluation of the registration process and good review practices in Saudi Arabia in comparison with Australia, Canada and Singapore. Pharmaceutical Medicine, 30(1), pp.37-47.

Herzig, P., Ameling, M. and Schill, A., 2012, August. A generic platform for enterprise gamification. In 2012 Joint Working IEEE/IFIP Conference on Software Architecture and European Conference on Software Architecture (pp. 219-223), Helsinki (Finland), 2012. IEEE.

Kang, J.G. and Han, K.H., 2008, November. A business activity monitoring system supporting real-time business performance management. In 2008 Third International Conference on Convergence and Hybrid Information Technology (Vol. 1, pp. 473-478), Busan (South Korea), 2008. IEEE.

Keeling, J.W., 2012. Development of systematic knowledge management for public health: a public health law ontology (Doctoral dissertation, Columbia University).

Landers, R.N., Auer, E.M., Collmus, A.B. and Armstrong, M.B., 2018. Gamification science, its history and future: definitions and a research agenda. Simulation \& Gaming, 49(3), pp.315-337.

Lawrence, X.Y. and Woodcock, J., 2015. FDA pharmaceutical quality oversight. International Journal of Pharmaceutics, 491(1-2), pp.2-7.

Machado, T.C.S., Pinheiro, P.R. and Tamanini, I., 2015. Project management aided by verbal decision analysis approaches: a case study for the selection of the best SCRUM practices. International Transactions in Operational Research, 22(2), pp.287-312. 
Marcão, R.P., Pestana, G. and Sousa, M.J., 2016, June. Corporate frameworks and technological products focusing alarmistic and monitoring incidators of control and performance. In 2016 11th Iberian Conference on Information Systems and Technologies (CISTI) (pp. 1-6). Gran Canaria (Spain), 2016. IEEE.

Marcão, R.P., Pestana, G. and Sousa, M.J., 2017, October. Gamification in project management. In Second International Conference On Economic and Business Managemen (FEBM 2017), Shanghai (China), 2017. Atlantis Press.

Marcão, R.P., Pestana, G. and Sousa, M.J., 2019. Performing enterprise architectures through gamified business models. In: G.L. Jamil, L.C. Jamil, C.R.M. Pessoa and W. Silveira. .Handbook of Research on Business Models in Modern Competitive Scenarios (pp. 232-246), United States of America. IGI Global.

Osipov, I.V., Nikulchev, E., Volinsky, A.A. and Prasikova, A.Y., 2015. Study of gamification effectiveness in online e-learning systems. International Journal of Advanced Computer Science and Applications, 6(2), pp.71-77.

Piras, L., Giorgini, P. and Mylopoulos, J., 2016. Acceptance requirements and their gamification solutions. In 2016 IEEE 24th International Requirements Engineering Conference (RE) (pp. 365-370), Beijing (China), September 2016. IEEE.

Robinson, E.P., 2001. Big Brother of modern management: e-mail monitoring in the private workplace. Labor Law Journal, 17, p.311.

Ryan, R.M. and Deci, E.L., 2000. Intrinsic and extrinsic motivations: classic definitions and new directions. Contemporary Educational Psychology, 25(1), pp.54-67.

Sailer, M., Hense, J.U., Mayr, S.K. and Mandl, H., 2017. How gamification motivates:an experimental study of the effects of specific game design elements on psychological need satisfaction. Computers in Human Behavior, 69, pp.371-380.

Singh, S.P., 2012. Gamification: a strategic tool for organizational effectiveness. International Journal of Management, 1(1), pp.108-113.

Turner, A.N., 1982. Consulting is more than giving advice. Harvard Business Review, 60(5), pp.120-129.

World Health Organization, 2006. Public health mapping and GIS for global health security: WHO strategic and operational framework (No. WHO/CDS/GIS/2006.1), Geneva, Switzerland: World Health Organization.

Yam, R.C., Lo, W., Tang, E.P. and Lau, A.K., 2011. Analysis of sources of innovation, technological innovation capabilities, and performance: an empirical study of Hong Kong manufacturing industries. Research Policy, 40(3), pp.391-402. 